\title{
Immunohistochemical Studies on the GABAergic System in the Rat Supraoptic Nucleus Using the PAP Method with an Application of Electron Microscopy
}

\author{
Koichi Injıma, ${ }^{1}$ Kazuo Oнtomo, ${ }^{1}$ Ryoji Kobayashi ${ }^{2}$ and Naosuke Kojıma ${ }^{1}$ \\ Department of Anatomy (Prof. K. IrJima) ${ }^{1}$ and Department of Biochemistry (Prof. Y. TAJima), ${ }^{2}$ Akita \\ University School of Medicine, Akita, Japan
}

Received August 11, 1986

Summary. GABAergic neuronal profiles in the supraoptic nucleus of the rat were immunohistochemically identified by using a purified GABA antibody with the peroxidase-antiperoxidase method. The localization of GABA-like immunoreactivity in nerve terminals on the neurosecretory neurons was examined electron microscopically.

A few small GABAergic neurons were found inside the supraoptic nucleus while only a very few medium-sized ones were detected in the perinuclear zone. Intrinsic, nonGABAergic small neurons covered by GABAergic neuropil were also detected. The neuropil with GABAergic axo-somatic synapses evenly encompassed unlabeled neurosecretory perikarya throughout the supraoptic nucleus. The GABAergic system seems to inhibit both vasopressin and oxytocin cells. In this area, glia cells showed clear outlines of unlabeled somata around counter-stained nuclei. Blood capillaries in the supraoptic nucleus were only slightly covered with a GABAergic neuropil.

Electron microscopic observations demonstrated the presence of GABAergic axo-somatic symmetrical and axo-dendritic asymmetrical synapses on the neurosecretory neurons. GABA-like immunoreactivity was localized on the membranes of microtubules and synaptic vesicles, on the external membranes of the mitochondria, and on the inner leaf of the presynaptic sites. Numerous pairs of non-immunoreactive synapses were arranged along these immunoreactive synapses.

Morphological studies with the Golgi-Cox method have identified small intrinsic neurons in the supraoptic nucleus of rats and rabbits (Felton and CAShner, 1979; Dyball and KemPLAy, 1982). Some electrophysiological studies have indicated the presence of inhibitory interneurons in the supraoptic nucleus of the rhesus monkey, dog and cat (Vincent and Hayward, 1970; Koizumi and Yamashita, 1972), but not of the rat (Kelly and DREIFUSS, 1970).

Judging from the distribution of glutamic acid decarboxylase (GAD), TAPPAz et al. (1983) suggested that neurosecretory neurons are under GABAergic control in the rat supraoptic nucleus. Demonstration of GAD, however, has not given clear evidenec for the presence of GABAergic interneurons in the nucleus (Meyer et al., 1980; Mugnaini and Oertel, 1985). Some authors have supported the presence of a small number of 
GABAergic neurons in the rat supraoptic area on the basis of presumptive concordance between the occurence of GABA-transaminase (GABA-T)-intensive neurons and that of GABA neurons (NAGAi et al., 1984; IrJima and Kojima, 1985). Recently, we (IIJima and KoJima, 1985) reported on the presence of medium-sized GABA-T-intensive neurons and more numerous small GABA-T-weakly positive neurons in the dorsal and ventral parts, respectively, of the perinuclear zone adjacent to the supraoptic nucleus, as well as relative lack of GABA-T within the nucleus.

Direct visualization of GABA-containing neurons has been achieved by STORMMAthisen et al. (1983) who used an antiserum against GABA by immunizing rabbits with GABA conjugated to bovine serum albumin. However, no immunohistochemical studies are available that apply GABA antibodies to the supraoptic nucleus, although GAMRANI et al. (1986) did study the rat hippocampus by the unlabeled peroxidase-antiperoxidase (PAP) method using GABA antibodies at the light and electron microscopic levels.

By the PAP method (STFRnBERGER, 1986), we examined the distribution of GABAergic neuronal elements in the supraoptic area at the light microscopic level, and the localization of the GABA-like immunoreactivity in nerve terminals on the neurosecretory neurons at the electron microscopic level, both by using purified GABA antibody. Cresylecht violet was used for the counterstain to help identification of the cell type (Shimizu and Imamoto, 1970).

\section{MATERIALS AND METHODS}

\section{Antibody production}

The GABA antibody was produced according to the method by STORM-MATHISEN et al. (1983). GABA $(100 \mu \mathrm{mol}$, Sigma A-2129) was conjugated to bovine serum albumin (BSA $12 \mathrm{mg}$ ) using $100 \mu \mathrm{mol}$ glutaraldehyde (GLA) in $2 \mathrm{ml} 0.1 \mathrm{M}$ sodium phosphate buffer at $\mathrm{pH} 7.4(0.1 \mathrm{M}-\mathrm{PB})$. The conjugation was performed at $20^{\circ} \mathrm{C}$ for $4 \mathrm{hrs}$. The conjugate was dialyzed against $0.15 \mathrm{M} \mathrm{NaCl}$ in $0.1 \mathrm{M}$ phosphate buffer (PBS), $\mathrm{pH} 7.4$, at $4^{\circ} \mathrm{C}$ for 20 hrs. After dialysis, the product $(1.5 \mathrm{ml})$ was emulsified with an equal volume of complete Freund's adjuvant. Three albino rabbits were subcutaneously injected at multiple sites with dosages of $1 \mathrm{ml}$ of suspension followed by similar injections every 2 weeks with the antigen in the incomplete adjuvant. The titer was monitered by the dot-immunobinding assay, becoming maximal after eight injections. The rabbits were bled 2 weeks after the last injection.

\section{Affinity purification of the antibody}

GABA $(500 \mu \mathrm{mol})$ was coupled with $1 \mathrm{~g}$ (dry gel) epoxy-activated Sepharose 6B (Pharmacia) as described by SundBerg and PoRATH (1974). This reaction was carried out in a $0.2 \mathrm{M}$ carbonate buffer, $\mathrm{pH} 11$, at $37^{\circ} \mathrm{C}$ for $16 \mathrm{hrs}$. The unreacting residue was blocked with $1 \mathrm{M}$ ethanolamine. The coupled gels were stored in PBS containing $0.1 \%$ sodium azide.

Dialyzed serum $(30 \mathrm{ml})$ was applied to a $15 \mathrm{ml}$ affinity column at $4{ }^{\circ} \mathrm{C}$ and the column was washed with $100 \mathrm{ml}$ PBS. The antibody was eluted with $4 \mathrm{M}$ magnesium chloride and $2 \mathrm{ml}$ fractions were collected in tubes. The fractions with the highest concentrations of the antibody were pooled, and dialyzed against PBS. The antibody was stored at $-80^{\circ} \mathrm{C}$ until use. 


\section{Dot-immunobinding analysis}

The specificity of the antibodies was tested by dot-immunobinding analysis as described by Ottersen and Storm-Mathisen (1984a), with some modifications. In brief, test substances of amino acids were conjugated to the dialyzed rat brain homogenate with GLA. After dialysis against 0.1M-PB, the conjugates were spotted onto nitrocellulose fllter paper (pore size $0.4 \mu \mathrm{m}$ ) using a Bio-dot microfiltration apparatus (Bio-rad) under slightly reduced pressure. The conjugates $(5 \mu \mathrm{l})$ were spotted on filter paper as uniform circles $3 \mathrm{~mm}$ in diameter. The filter paper was air dried, washed briefly in the blotting buffer ( $25 \mathrm{mM}$ Tris and $0.2 \mathrm{M}$ glycine in $5 \%$ methanol), and incubated sequentially in three different solutions at $20^{\circ} \mathrm{C}$ for $1 \mathrm{hr}$ each: a) in $0.15 \mathrm{M} \mathrm{NaCl}$ in $10 \mathrm{mM}$ Tris- $\mathrm{HCl}$ at $\mathrm{pH} 7.5$ (TBS) containing $2 \%$ gelatin to block any unoccupied protein binding sites on the filter paper; $b)$ with the antiserum or affinity purified antibody (100 $\mu 1$ immune serum or $50 \mu \mathrm{l}$ affinity purified antibody in $10 \mathrm{ml}$ TBS containing $1 \% \mathrm{BSA}$ ); and c) in goat anti-rabbit IgG conjugated with horseradish peroxidase $(20 \mu \mathrm{l}$ serum in $10 \mathrm{ml}$ TBS containing $2 \%$ gelatin). The filter paper was washed with five changes of $0.3 \%$ Tween 20 in TBS within the 25-min interval between incubations. After the final incubation, the filter paper was washed with Tween 20 in TBS, and placed in a solution of $0.05 \%$ diaminobenzidine- $\mathrm{HCl}(\mathrm{DAB}$, Sigma) and $0.02 \%$ hydrogen peroxide in $50 \mathrm{mM}$ Tris- $\mathrm{HCl}$ buffer, $\mathrm{pH} 7.5$ (50 mM-TB) for 2-3 min for the detection of the peroxidase conjugated to the second antibody. The reaction was curtailed by washing the paper in distilled water. The filter paper was dried, and immersed in decahydronaphthalene. The transparent nitrocellulose paper was then placed in a densitometer (Cosmo F808) and the optical density in the stained spots was measured at $590 \mathrm{~nm}$ (Fig. 1 and Table 1).

\section{Tissue preparation for immunohistochemistry}

Ten female Wistar rats (body weight 180-200 g) were anesthetized with sodium pentobarbital ( $50 \mathrm{mg} / \mathrm{kg}$ i.p.) and underwent thoracotomy under artificial respiration. After ligation of the descending aorta, 100 I.U. of heparin was injected into the left ventricle. The animal was transcardially perfused first with $10 \mathrm{ml}$ of ice cold PBS for $1 \mathrm{~min}$, and then with $80-100 \mathrm{ml}$ of an ice cold fixative solution (4\% paraformaldehyde, $0.5 \%$ glutaraldehyde and $0.2 \%$ picric acid in $0.1 \mathrm{M}-\mathrm{PB}, \mathrm{pH} 7.4$ ) for $10 \mathrm{~min}$. The brain was excised after perfusion. The hypothalamus was sliced into $5 \mathrm{~mm}$ thick frontal blocks and postfixed in the same fixative solution without glutaraldehyde at $4^{\circ} \mathrm{C}$ for $4 \mathrm{hrs}$. The cerebellum was treated in the same manner as the hypothalamus for a positive control.

For light microscopy, the blocks were immersed in $15 \%$ and $30 \%$ sucrose in $0.1 \mathrm{M}$ PB for 1 day, each. Serial frozen sections $(15 \mu \mathrm{m}$ thick) were cut in a cryostat and stored in $0.05 \%$ Triton X-100 in PBS (PBS-T) at $4^{\circ} \mathrm{C}$ for 2 days. The immunohistochemical staining for GABA was done on free floating sections of eight brains according to the PAP method (STERNBERGER, 1986) with counterstaining using cresylecht violet.

For electron microscopy, after postfixation, $30 \mu \mathrm{m}$ thick frontal sections of two brains were cut on a Vibratome (Oxford), rinsed for $2 \mathrm{hrs}$ in $0.1 \mathrm{M}$ Tris buffer ( $\mathrm{pH}$ 7.4) and processed for immunohistochemistry according to the PAP method (STERNBERGER, 1986).

\section{Immunohistochemical reaction}

The sections were immunohistochemically stained by the PAP method using the purified anti-GABA antibody obtained in our laboratory. 
The staining procedure was as follows: the sections were a) pretreated with $2 \%$ normal goat serum (NGS) in PBS-T for light microscopy or PBS for electron microscopy at $20^{\circ} \mathrm{C}$ for $2 \mathrm{hrs}$; b) incubated in the first antibody solution (1\% NGS and $0.5 \%$ BSA in PBS-T for light microscopy, or PBS for electron microscopy containing the purified anti-GABA antibody, dilution rate, $1: 800$ ) at 4 $\mathrm{C}$ for 3 days; c) incubated in the goat anti-rabbit IgG (Miles) in PBS-T for light microscopy, or PBS for electron microscopy $(1: 500)$ at $20^{\circ} \mathrm{C}$ for $2 \mathrm{hrs}$; d) incubated in the rabbit PAP in PBS-T for light microscopy, or PBS for electron microscopy $(1: 500)$ at $20^{\circ} \mathrm{C}$ for $2 \mathrm{hrs}$; e) treated with the DAB solution (50 $\mathrm{mg}$ DAB and $0.01 \%$ hydrogen peroxidase in $100 \mathrm{ml} 50 \mathrm{mM}-\mathrm{TB}$ ) at $20^{\circ} \mathrm{C}$ for $6-8 \mathrm{~min}$; and finally f) rinsed with $50 \mathrm{mM}$-TB for $30 \mathrm{~min}$. The sections were washed with three changes of PBS for 30 min after each incubation.

At this point the sections were mounted on gelatin coated glass slides, dried at $37^{\circ} \mathrm{C}$ overnight, counterstained with $0.25 \%$ cresylecht violet (Chroma) for $4 \mathrm{~min}$, dehydrated with the ethanol series, cleared with xylene, and cover-slipped with Permount (Fisher).

To control for nonspecific staining, the antiserum to rat GABA was replaced in the staining sequence (b) by the normal rabbit serum.

Slices of the cerebellum, where the distribution of GABAergic neurons has been thoroughly established (Nagai et al., 1983; Ottersen and Storm-Mathisen, 1984b), were used as a positive control.

\section{Electron microscopy for identifying GABAergic synapses}

After the DAB reaction, the sections were postfixed for $1 \mathrm{hr}$ in $1 \%$ osmium tetroxide, dehydrated in graded ethanol (50-100\%) and embedded in Epon 812. Semi-thin ( $1 \mu \mathrm{m})$ and thin sections $(60-80 \mathrm{~nm})$ were cut with a glass knife in an LKB 8800-III ultramicrotome. The semi-thin sections were stained for light microscopic observation with a hot aqueous solution of $0.5 \%$ toluidine blue. The ultrathin sections were collected on copper grids (150 mesh), stained with saturated alcoholic uranyl acetate, and examined with a JEOL $100 \mathrm{C}$ electron microscope.

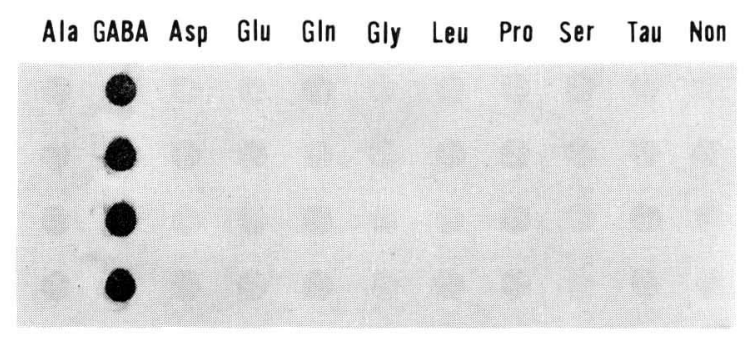

Table. 1.

\begin{tabular}{lrl}
\hline Test substance & Relative absorbance $(\%)$ \\
\hline GABA & 100.0 & \\
Alanine & $5.4 \quad \pm 0.4$ \\
Aspartate & $1.7 \quad \pm 0.3$ \\
Glutamic acid & 2.4 & \pm 1.1 \\
Glutamine & 3.6 & \pm 0.7 \\
Glysine & $2.3 \pm \pm 0.9$ \\
Leucine & 2.5 & \pm 1.3 \\
Proline & 5.1 & \pm 0.8 \\
Serine & $2.0 \quad \pm 0.7$ \\
Taurine & $5.1 \quad \pm 1.1$
\end{tabular}

Fig. 1. and Table 1. Cross-reactivity of the purified anti-GABA antibody to various amino acids conjugated with the rat brain macromolecules by glutaraldehyde and spotted onto the nitrocellulose filter paper.

Fig. 1. Photograph of the filter paper showing the reaction to the purified anti-GABA antibody. Dilution rate $1: 200$.

Table 1. The relative absorbance in the stained spots measured by a densitometer (Cosmo F808) at $590 \mathrm{~nm}$. The data of the second column were obtained from the comparison to the absolute absorbance of the stained spot for GABA. The third column indicates the standard error in measurement for each amino acid. 


\section{RESULTS}

In the dot-immunobinding assay described above, the purified GABA antibody stained the GABA-protein conjugate intensely, while it stained the other conjugates only slightly (Fig. 1 and Table 1). The cross-reactivity against alanine, taurine and glutamate was $5.4 \%, 5.1 \%$ and $2.4 \%$, respectively (Table 1 ). In addition to the dotimmunobinding assay, the usefulness of the antibody was tested by an immunohistochemical technique. Control sections incubated with the normal rabbit serum revealed slight, nonspecific staining without showing any particular localization. The cerebellum, used here as a positive control, revealed prominent immunoreactivity to the purified GABA antiserum. Localization and intensity of the reaction were similar to those described by OtTERSEn and Storm-Mathisen (1984b).

\section{The distribution of GABA-like immunoreactivity (GABA-LI)}

Dilution of the primary antibody to 1:800 eliminated any increased staining at the edges of a section. The somata of the neurosecretory neurons did not show any immunoreactivity. The optic tract revealed very faint immunostaining (Fig. 2). The walls of most blood capillaries inside the supraoptic nucleus showed slight staining in the surrounding neuropil (Fig. 7), whereas the tangentially cut relatively large blood vessels close to the perinuclear zone exhibited a fine reticular network outside the endothelium; the network appeared to connect with the adjacent GABAergic neuropil in

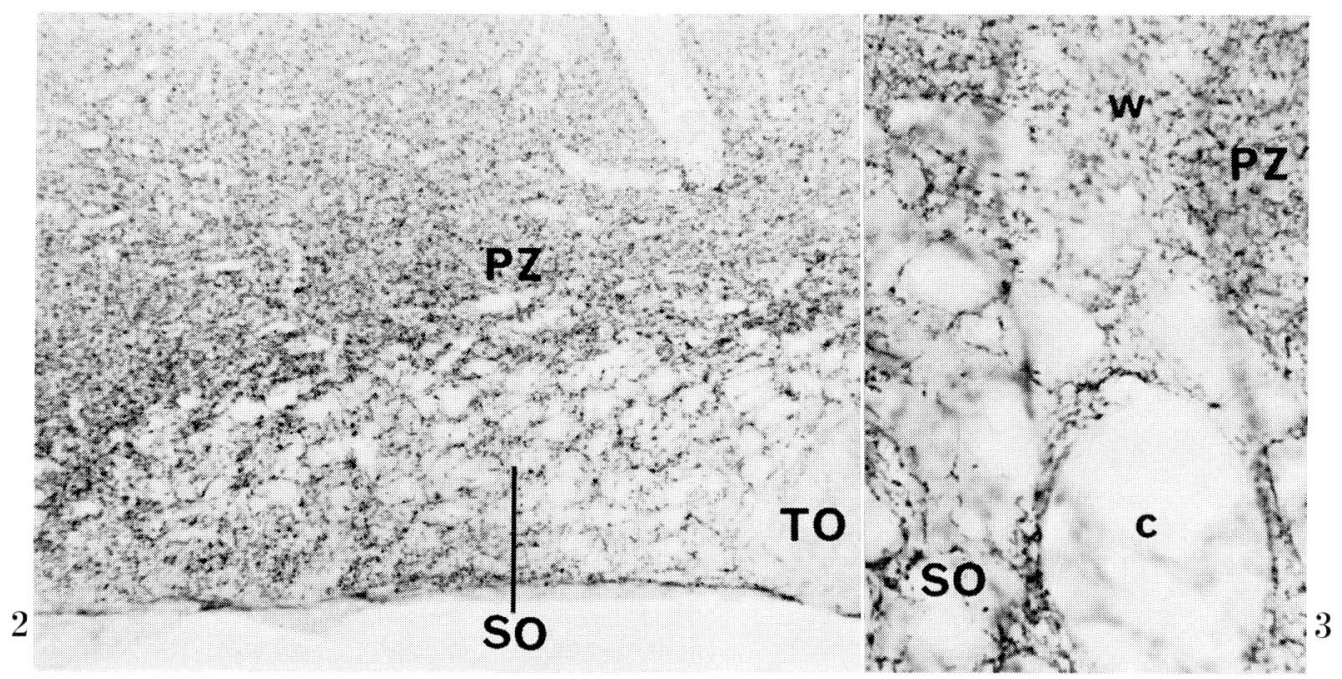

Fig. 2 and 3. Photomicrographs showing the distribution of GABA-like immunoreactivity in the frontal sections of the supraoptic area by the PAP method without counterstaining. Dilution rate $1: 800$

Fig. 2. Low power photomicrograph showing the whole supraoptic area (SO) adjacent to the optic tract $(T O)$ and the perinuclear zone $(P Z)$ closely dorsal to the supraoptic nucleus. Note negative images of the optic tract and many neurosecretory neurons in the supraoptic nucleus. The neuropil in the perinuclear zone reveals a stronger reaction than that in the supraoptic nucleus. $\times 150$

Fig. 3. Medium-power photomicrograph showing the wall surface of a tangentially cut blood vessel (c) at the dorsal limit of the supraoptic nucleus (SO). A labeled, fine reticuler network (w) continuing to the adjacent GABAergic neuropil in the supraoptic nucleus and perinuclear zone $(P Z)$ is seen on that surface. $\times 375$ 

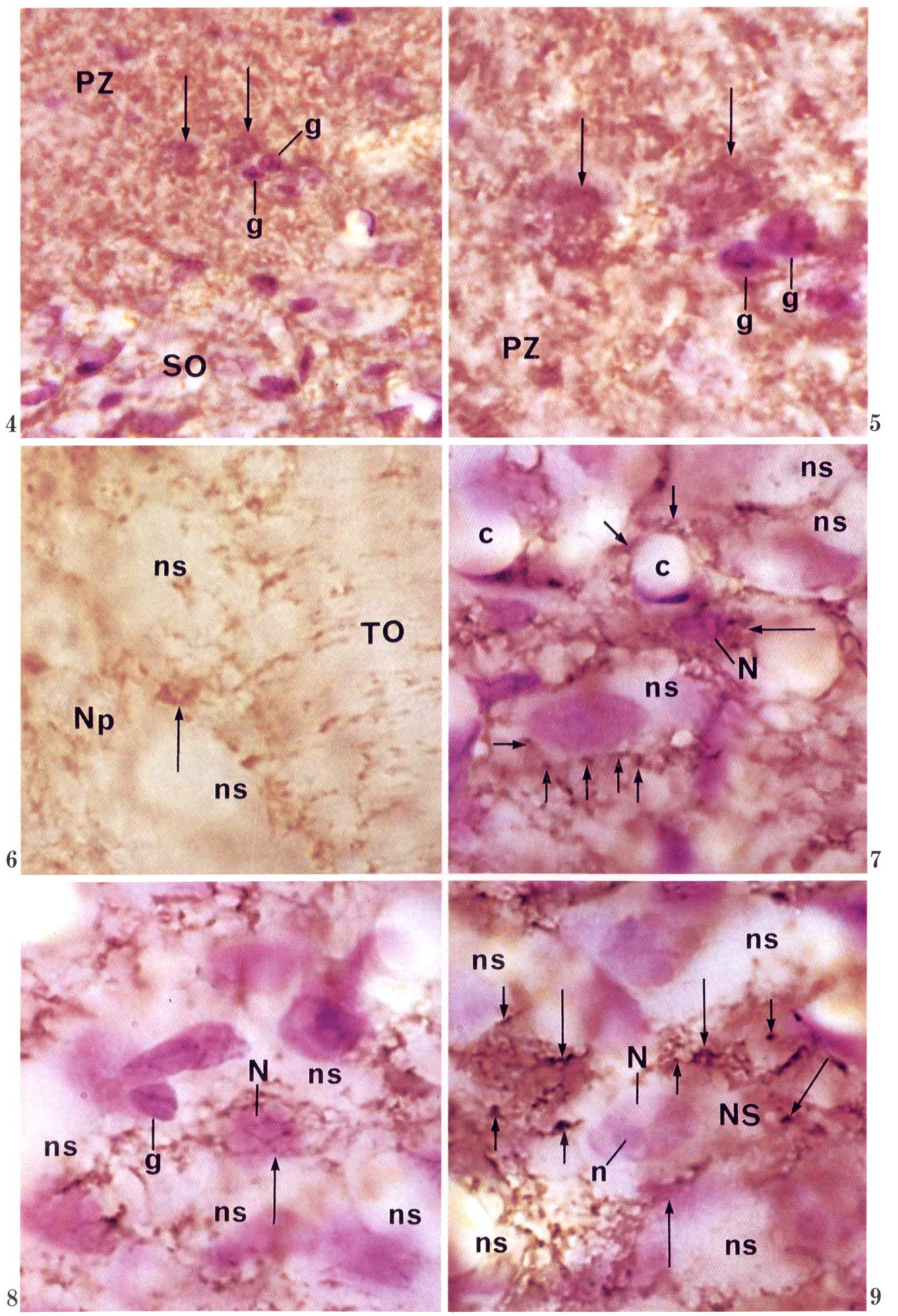

Fig. 4-9. Legends on the opposite page. 


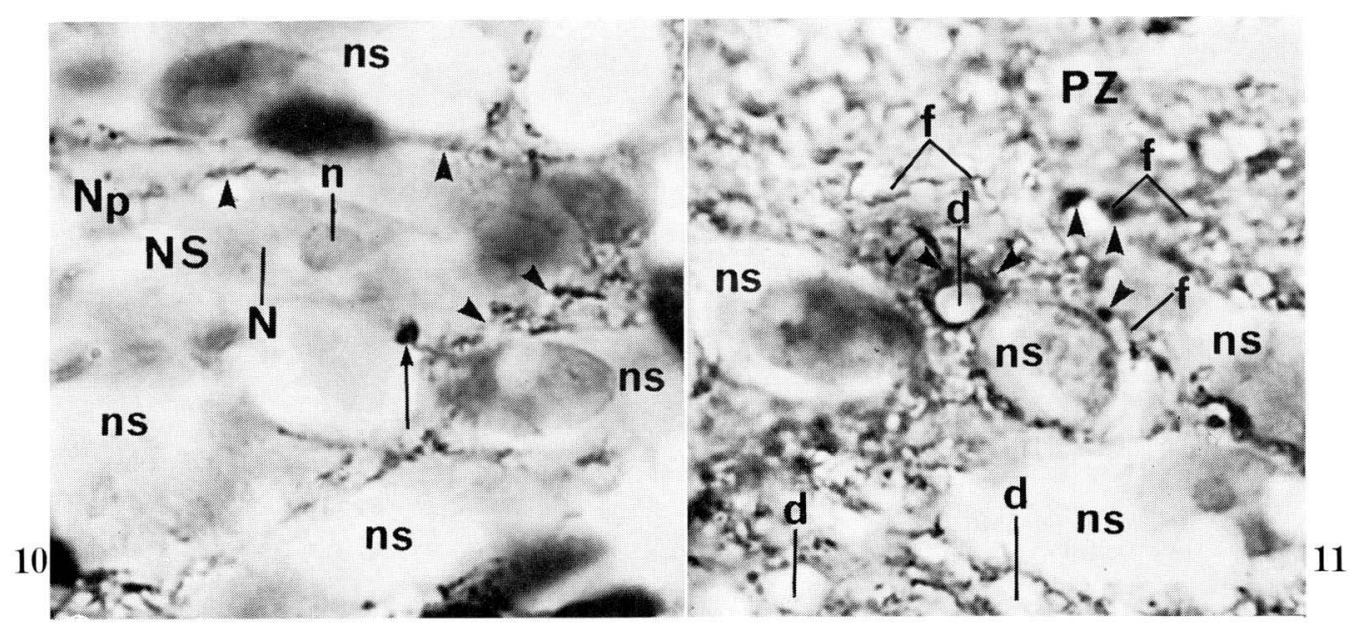

Fig. 10 and 11. High power photomicrographs showing the distribution of GABA-like immunoreactivity mainly in cell processes of the supraoptic area by the PAP method with counterstaining by cresylecht violet. Dilution rate 1:800. $\times 1,500$

Fig. 10. Immunoreactive varicosities (arrowheads) and a swelling (arrow) possibly indicating an axo-somatic synapse are seen around the perikaryon of a neurosecretory neuron (NS) whose nucleus $(N)$ and nucleolus $(n)$ are counterstained. Neighboring neurosecretory perikarya (ns) are not immunostained, but outlined with the GABA-positive neuropil.

Fig. 11. Profiles of presumptive dendrites of neurosecretory neurons (d) are located in close proximity to their perikarya $(n s)$. Varicosities (arrowheads) of immunostained nerve fibers $(f)$ are visible. $P Z$ perinuclear zone.

Fig. 4-9. Photomicrographs showing the distribution of GABA-like immunoreactivity in the supraoptic area by the PAP method. Dilution rate $1: 800$. The counterstain with cresylecht violet, except for Figure 6. Fig. 4: $\times 375$, Fig. 5-9: $\times 1,500$

Fig. 4. The neuropil in a dorsal part of the supraoptic nucleus $(S O)$ and the perinuclear zone $(P Z)$ showing GABA-like immunoreactivity. In the perinuclear zone, two medium-sized neurons (arrows) are immunostained, while two glia cells close to them $(\mathrm{g})$ are not labeled.

Fig. 5. A part of Figure 4 in closer view. The two counter-stained nuclei of medium-sized neurons (arrows), which are densely surrounded by an immunostained neuropil in the perinuclear zone $(P Z)$, are encompassed by thin diffusely immunostained perikarya. Glia cells $(g)$ show counterstained nuclei only.

Fig. 6. A small immunostained intrinsic neuron is indicated by an arrow. Note that GABA-like immunoreactivity is localized in its perikaryon. Immunoreactive neuropil ( $N p$ ) encompasses unlabeled neurosecretory perikarya ( $n s)$. The optic tract (TO) is essentially free of immunoreactivity. No counterstain.

Fig. 7. A small fusiform neuron at the center (arrow) shows diffuse and moderate immunoreactivity in the perikaryon surrounding the counterstained nucleus $(N)$. This cell is heavily covered by the GABA-immunoreactive neuropil including stained terminal swellings. The perikarya of neighboring neurosecretory neurons ( $n s$ ) and a capillary wall (c) appear to be also covered with immunostained swellings (short arrows).

Fig. 8. A presumptive exicitatory interneuron (arrow) with a small counterstained nucleus $(N)$ is seen at the center. Its perikaryon, immunonegative itself is densely covered by an immunopositive neuropil with some terminal swellings. The neurosecretory perikarya ( $n s$ ) are immunonegative. A nearby glia cell $(g)$ is neither immunostained nor surrounded by a stained neuropil.

Fig. 9. Separate four groups of axonal branching (arrows) innervate the immunonegative perikaryon of a neurosecretory neuron (NS). This cell shows the counterstained nucleus (N) and a nucleolus $(n)$. Each axonal plexus appears to terminate in synapses (short arrows) on that soma (NS) as well as somata (ns) of other neurosecretory neurons surrounding this cell. 
the supraoptic area (Fig. 3). Glia cells showed no immunoreactivity (Fig. 4, 5, 8).

Very few medium-sized GABA-immunoreactive neurons were detected in the perinuclear zone adjacent to the supraoptic nucleus (Fig. 4, 5). There were only a few small GABA-immunoreactive neurons inside the nucleus. These possessed oval or fusiform nuclei and diffusely labeled cytoplasm, and were densely covered by a more darkly stained GABA-immunoreactive neuropil containing presumptive terminals (Fig. 6, 7). Fiber connections between these two groups of GABA-immunoreactive neurons in and outside the supraoptic nucleus could not be confirmed. In addition, another type of small neurons was more frequently detected within the supraoptic nucleus, whose perikarya were immunonegative, but tightly surrounded by a reticular GABA-positive neuropil including some apparent terminals (Fig. 8).

There were many profiles of GABA-immunoreactive fine cell processes which presumably represented extrinsic nerve fibers (Fig. 9, 10); they were evenly distributed throughout the supraoptic nucleus. These processes appeared to terminate in GABAimmunoreactive synapses on the neurosecretory neurons after moderate branching (Fig. 9, 11). In addition, labeled nerve fibers, often showing immunoreactive varicosities (Fig. 10,11) appeared to end in fine dots or knobs on these neurons (Fig. 9, 10).

Electron microscopic observations showed that immunoreactivity for GABA was localized on the external membrane of synaptic vesicles, microtubules, mitochondria and on the inner leaf of the presynaptic sites (Fig. 13-15), and that only some of the nerve terminals around the neurosecretory neurons were GABA-immunopositive ones, which formed axo-somatic symmetrical (Fig. 12-14) and axo-dendritic asymmetrical (Fig. 15) synapses. Many other synapses were immunonegative and arranged side by side along the immunopositive synapses (Fig. 14).

In the supraoptic area and the cerebellum, the nuclei of the GABA-immunopositive neurons revealed much less reactivity than their cytoplasm.

\section{DISCUSSION}

Recently, Storm-Mathisen and colleagues have demonstrated GABA-containing neurons by using an antibody against GABA (STORM-MATHisen et al., 1983; OtTERSEN and Storm-Mathisen, 1984b). However, their GABA antibody cross-reacted with amino acids such as taurine, leucine and glutamate at rates of 5-20\%. Other authors proved that the anti-GABA antibody, obtained according to this method, was useful for detecting GABAergic elements immunohistochemically, and that the GABA antiserum

Fig. 12-15. Electron micrographs showing the localization of GABA-immunoreactivity in synapses on the neurosecretory neurons of the supraoptic nucleus by the PAP method. Dilution rate 1:800. $n s$ Neurosecretory perikaryon, $N$ nucleus, $m$ mitochondria, $s g$ neurosecretory granules, $s v$ synaptic vesicles, $t$ microtubules, $A$ axon, $D$ dendrite, $N p$ neuropil.

Fig. 12. Electron micrograph showing a immunostained axosomatic synapes (upper left corner) on the immunonegative neurosecretory perikaryon, where neurosecretory granules are visible. $\times 13,000$

Fig. 13. The axo-somatic symmetrical synapse in Figure 12 in higher magnification. GABA-like immunoreactivity is localized on the membranes of synaptic vesicles and microtubules, external membranes of mitochondria and on the inner leaf of the presynaptic site. A secretory granule and a mitochondrion are immunonegative in the neurosecretory perikaryon. $\times 27,000$

Fig. 14. A GABA-immunoreactive (upper) and negative (lower) axo-somatic symmetrical synapses are arranged side by side on a neurosecretory perikaryon. The former exhibits the identical distribution of GABA-like immunoreactivity to that in Figure 13. $\times 31,000$

Fig. 15. An GABA-immunoreactive axo-dendritic asymmetrical synapse. $\times 36,000$ 


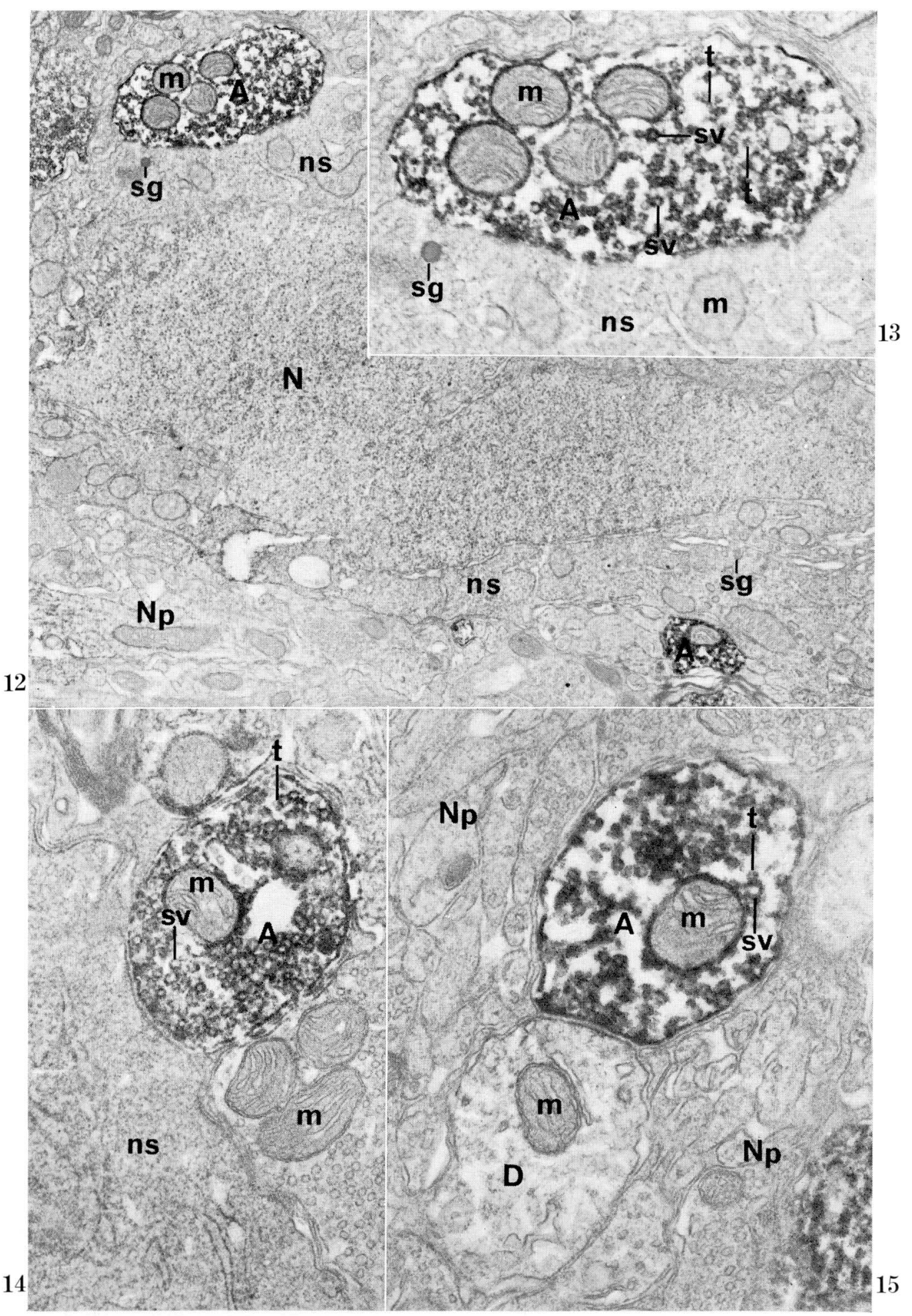

Fig. 12-15. Legends on the opposite page. 
cross-reacted with some amino acids (Hodgson et al., 1985; Somogyi et al., 1984, 1985; Somogyi and Hogdson, 1985; Saito and Tanaka, 1986).

We recognized a positive immunoreactivity for GABA in the cerebellar cortex (used as a positive control) and its distribution corresponded closely to that described by GABA-immunohistochemistry (STorm-Mathisen et al., 1983; OtTERSEn and StormMathisen, 1984b) and by GAD-immunohistochemistry (SAito et al., 1974), The immunostaining was most evident when the antiserum was diluted to 1:800 for the PAP method (STERnBerger, 1986). Our antibody had a higher titer compared with that reported by STORM-MATHISEN et al. (1983).

As shown in Figure 1 and Table 1, the purified GABA antibody showed a slight cross-reactivity against alanine, taurine and glutamate. Since the concentrations of alanine and taurine in the supraoptic nucleus are very low, the nucleus has been ruled out in the chemoarchitecture with regard to the amino acids (NieuwenhuYs, 1985; Ottersen and Storm-Mathisen, 1984b). Whether or not alanine and taurine are neurotransmitters remains to be confirmed (Nieuwenhuys, 1985; Saito and Tanaka, 1986). Although many perikarya with glutamate-like immunoreactivity (Glu-LI) were found in all hypothalamic nuclei of the mouse (OtTERSEN and Storm-Mathisen, 1984b), the purified GABA antibody did not stain the neurons in the supraoptic nucleus except for the few small neurons under consideration. In our control experiments, it failed to stain cerebellar granule cells, which had been reported to be immunopositive for glutamate (STORM-MATHISEN et al., 1983).

Nuclei of GABA-immunopositive neurons in the supraoptic nucleus and the cerebellum of the rat show much less immunoreactivity than their perikarya; this differs from neurons in the myenteric plexus of the guinea pig ileum, where both nuclei and perikarya are immunostained similarly with GABA antibodies (SAITo and TANAKA, 1986). The reason for this discrepancy remains unclear.

Very few medium-sized neurons were immunostained for GABA in the perinuclear zone adjacent to the supraoptic nucleus. This indicates that GABA containing neurons may be restricted to a part of the GABA-T-storongly positive neurons in this zone (IIJIMA and KoJIma, 1985). The discrepancy between the distribution of GABA-T and GABA indicates that the coincidence of the GABA-T-intensive neurons with the GABA immunopositive neurons proposed in the rat brain (NAGAI et al., 1983, 1984, 1985) may not be so definite in the supraoptic area. The present findings in the rat perinuclear zone favor the previously reported concept on the presence of inhibitory relay neurons that monophasic specific osmosensitive cells in the perinuclear zone are involved in the osmoreceptor-supraoptic nuclear complex and that these cells partly include inhibitory neurons, at least in the primates (VINCENT and HAYwARD, 1970; HAYWARD and VinCENT, 1970).

The distribution of profiles of GABAergic, presumptive afferent nerve fibers arising mostly from the nucleus accumbens (MEYER et al., 1980) was not restricted to either the vental or dorsal division of the supraoptic nucleus in our study. The distribution pattern of these fibers within the nucleus indicates that GABAergic fibers inhibit both vasopressin and oxytocin cells to the same degree (Rodes et al., 1981; Swanson et al., 1981; Kawata and Sano, 1985).

The present electron microscopic observations (Fig. 12-15) demonstrated the presence of GABAergic axo-somatic and axo-dendritic synapses on the neurosecretory neurons, and showed that the localization of GABA-like immunoreactivity is different from that reported in the hippocampus by GAMRANI et al. (1986), especially in regard to the immunostaining in the membranes of micrtubules and the inner leaf of the presynaptic membrane in the present study. 
The localization of GABA-like immunoreactivity in these labeled synapses is consistent with that of the GAD in the synapses of the cerebellum revealed by the PAP method (OERTEL et al., 1981). The many immunonegative synapses on the neurosecretory somata may represent the pericellularly arranged noradrenergic and serotonergic synaps already reported immunohistochemically in the rat supraoptic nucleus (Sawchenko and Swanson, 1981; Kawata and Sano, 1985).

Observations similar to ours have been reported by using the PAP method with GAD- or GABA-antisera by light microscopy in the cerebellum and the nucleus tractus solitarius (Saito et al., 1974; Maley and Newton, 1985), and by electron microscopy in the cerebellum, dorsal raphe nucleus and hippocampus (McLaughlin et al., 1974; Oertel et al., 1981; Nanopoulos et al., 1982; Gamrani et al., 1986). In general, these studies are in agreement as regards the identical distribution pattern of GAD and GABA in the nerve terminals.

Consequently, the present results by light and electron microscopy together with the previous reports demonstrate that the GABAergic axo-somatic symmetrical and axo-dendritic asymmetrical synapses innervate the neurosecretory neurons of the rat supraoptic nucleus. This study provides immunohistochemical evidence for the presence of direct GABAergic projections to the neurosecretory neurons in this nucleus.

A few small GABAergic local circuit neurons (Mugnaini and OerTel, 1985) were found in the rat supraoptic area (Fig. 4-7), which is in agreement with the previous positive results shown by the GABA-T reaction (IIJImA and KoJimA, 1985) as well as by the experimental GAD assay study (MEYer et al., 1980). Although Kelly and Dreifuss (1970) ruled out the possibility that inhibitory interneurons in the rat are involved in the axon collateral system of the supraoptic nucleus, Korzumi and Yamashita (1972) demonstrated their presence electrophysiologically in the dog and cat. Cultured supraoptic cells of puppies showed inhibitory responses to GABA (SAKAI et al., 1974). The negative results obtained electrophysiologically by THOMson (1984) may reflect the paucity of inhibitory interneurons in the rat supraoptic nucleus, because SGRo et al. (1984) recorded marked inhibition from a cell in the same area. Further studies are needed to justify the present hypothesis.

The present results indicate that small non-GABAergic neurons covered with a dense GABAergic neuropil are more numerous than the GABAergic neurons in the supraoptic nucleus. SGRo et al. (1984) have reported electrophysiologically that more excitatory interneurons are present in the rat supraoptic area than inhibitory neurons, and that the former may play a role as an amplifier to the afferent impulse from the subfornical organ. The non-GABAergic neurons under consideration most probably represent excitatory interneurons in the rat supraoptic area reported by SGRo et al. (1984).

Acknowledgments: The authors are grateful to Mr. Mitsutaka MiURa for his technical assistance.

\section{REFERENCES}

Dyball, R. E. J. and S. K. Kemplay : Dendritic trees of neurons in the supraoptic nucleus. Neuroscience 7: 223-230 (1982).

Felton, D. L. and K. A. Cashner : Cytoarchitecture of the supraoptic nucleus. Neuroendocrinology 29: 221-230 (1979). 
Gamrani, H., B. Onteniente, P. Seguela, M. Geffard and A. Calas : $\gamma$-aminobutyric acidimmunoreactivity in the rat hippocampus. A light and electron microscopic study with antiGABA antibodies. Brain. Res. 364: 30-38 (1986).

Hayward, J. N. and J. D. Vincent: Osmosensitive single neurons in the hypothalamus of unanaesthetized monkeys. J. Physiol. 210: 947-972 (1970).

Hogdson, A. J., B. Pente, A. Erdei, J. W. Chubb and P. Somogyi : Antisera to $\gamma$-aminobutyric acid. I. Production and characterization using a new model system. J. Histochem. Cytochem. 33: 229-239 (1985).

Iijima, K. and N. Kojima : GABA-T-positive neurons in the rat supraoptic nucleus as revealed by a pharmaco-histochemical method with gabaculine. Acta histochem. cytochem. 18: 445-454 (1985).

Kawata, M. and Y. Sano: Immunocytochemical identification of the peptidergic neurons in the paraventricular and supraoptic nuclei. In: (ed. by) H. Kobayashi, H. A. Bern and A. Urano: Neurosecretion and the biology of neuropeptides. Japan Scientific Publishing Co., Tokyo, and Springer-Verlag, Berlin-Heidelberg-New York-Tokyo, 1985 (p. 162-164).

Kelly, J. S. and J. J. Dreifuss : Antidromic inhibition of identified rat supraoptic neurons. Brain Res. 22: 406-409 (1970).

Koizumi, K. and H. Yamashita : Studies of antidromically identified neurosecretory cells of the hypothalamus by intracellular and extracellular recordings. J. Physiol. (Lond.) 221: 683-705 (1972).

Maley, B. and B. W. Newton: Immunocytochemistry of $\gamma$-aminobutyric acid in the cat tractus solitarius. Brain Res. 330: 201-207 (1985).

McLaughlin, B. J., J. G. Wood, K. Saito, R. Barber, J. E. Vaugn, E. Roberts and J.-Y. Wu : The fine structural localization of glutamate decarboxylase in synaptic terminals of rodent cerebellum. Brain Res. 76: 377-391 (1974).

Meyer, D. K., W. H. Oertel and H. J. Brownstein : Deafferentiation studies on the glutamate acid decarboxylase content of the supraoptic nucleus of the rat. Brain Res. 200: 165-168 (1980).

Mugnaini, E. and W. H. Oertel : An atlas of the distribution of GABAergic neurons and terminals in the rat $\mathrm{CNS}$ as revealed by GAD immunohistochemistry. In: (ed. by) A.Björklund, T. Hökfelt and M. J. Kuhar: Handbook of chemical neuroanatomy, Vol. 4: GABA and neuropeptides in the CNS Part I. Elsevier, Amsterdam-New York-Oxford, 1985 (p. 436-608).

Nagai, T., T. Maeda, H. Imai, P. L. McGeer and E. G. McGeer : Distribution of GABA-T-intensive neurons in the rat hindbrain. J. comp. Neurol. 231: 260-269 (1985).

Nagai, T., P. L. McGeer, M. Araki and E. G. McGeer: GABA-T-intensive neurons in the rat brain. In: (ed. by) A. Björklund, T. Hökfelt and M. J. Kuhar: Handbook of chemical neuroanatomy, Vol. 3: Classical transmitters and transmitter receptors in the CNS, Part II. Elsevier, Amsterdam-New York-Oxford, 1984 (p. 247-272).

Nagai, T., P. L. McGeer and E. G. McGeer: Distribution of GABA-T-intensive neurons in the rat forebrain and midbrain. J. comp. Neurol. 218: 220-238 (1883).

Nanopoulos, D., M. F. Belin, M. Maitre, G. Vincendon and J. F. Pujol : Immunocytochemical evidence for the existence of GABAergic neurons in the nucleus raphe dorsalis. Possible existence of neurons containing serotonin and GABA. Brain Res. 232: 375-389 (1982).

Nieuwenhuys, R.: Amino acids.: In: Chemoarchitecture of the brain. Springer-Verlag, BerlinHeidelberg-New York-Tokyo, 1985 (p. 48-52).

Oertel, W. H., D. E. Schmechel, E. Mugnaini, M. L. Tappaz and I. J. Kopin : Immunocytochemical localization of glutamate decarboxylase in rat cerebellum with a new antiserum. Neuroscience 6: 2715-2735 (1981).

Ottersen, O. P. and J. Storm-Mathisen: Glutamate- and GABA-containing neurons in the mouse and rat brain, as demonstrated with a new immunocytochemical technique. J. comp. Neurol. 229: 374-392 (1984a).

: Neurons containing or accumulating transmitter amino acids. In: (ed. by)

A. Björklund, T. Hökfelt and M. J. Kuhar: Handbook of chemical neuroanatomy, Vol. 3: Classical transmitters and transmitter receptors in the CNS, Part II. Elsevier, Amsterdam-New YorkOxford, 1984b (p. 141-246). 
Rodes, C. H., J. I. Marcell and D. W. Pfaff : Immunocytochemical analysis of magnocellular elements in rat hypothalamus, distribution and number of cells containing neurophysin, oxytocin, and vasopressin. J. comp. Neurol. 198: 45-64 (1981).

Saito, K., R. Barber, J.-Y. Wu,, T. Matsuda, E. Roberts and J. E. Vaughn : Immunocytochemical localization of glutamate decarboxylase in rat cerebellum. Proc. Nat. Acad. Sci. USA 71: 269-273 (1974).

Saito, N. and C. Tanaka : Immunohistochemical demonstration of GABA containing neurons in the guinea pig ileum using purified GABA antiserum. Brain Res. 376: 78-84 (1986).

Sakai, K. K., B. H. Marks, J. M. George and A. Koestner : The isolated organ-cultured supraoptic nucleus as a neuropharmacological test system. J. Pharmacol. exp. Therap. 190: 482-491 (1974).

Sawchenko, P. E. and L. W. Swanson: Central noradrenergic pathways for the integration of hypothalamic and autonomic responses. Science 214: 685-687 (1981).

Sgro, S., A. V. Ferguson and L. P. Renaud: Subfornical organ-supraoptic connections: An electrophysiological study in the rat. Brain Res. 303: 7-13 (1984).

Shimizu, N. and K. Imamoto: Fine structure of the locus coeruleus in the rat. Arch. histol. jap. 31: 229-246 (1970).

Somogyi, P. and A. J. Hogdson : Antisera to $\gamma$-aminobutyric acid. III. Demonstration of GABA in Golgi-impregnated nerves and in conventional electron microscopic sections of cat striate cortex. J. Histochem. Cytochem. 33: 249-257 (1985).

Somogyi P., A. J. Hogdson, A. D. Smith, M. G. Munzil, A. Gorio and J.-Y. Wu : Different populations of GABAergic neurons in the visual cortex and hippocampus of cat contain somatostatin- or cholecystokinin-immunoreactive material. J. Neurosci. 4: 2590-2603 (1984).

Somogyi, P., A. J. Hogdson, I. W. Chubb, B. Penke and A. Erdei : Antisera to $\gamma$-aminobutyric acid. II. Immunocytochemical application to the central nervous system. J. Histochem. Cytochem. 33: 240-248 (1985).

Sternberger, L. A.: The unlabeled antibody peroxidase-antiperoxidase method. In: Immunocytochemistry. 3rd. Ed. John Wiley \& Sons, New York-Chichester-Brisbane-Toronto, 1986 (p. 90 209).

Storm-Mathisen, J., A. K. Leknes, A. T. Bore, J. L. Vaaland, P. Edmisson, F. M. S. Haug and O. P. Ottersen: First visualization of glutamate and GABA in neurons by immunocytochemistry. Nature 301: 517-520 (1983).

Sundberg, L. and J. Porath : Preparation of absorbents for biospecific affinity chromatography. J. Chromatogr. 80: 87-98 (1974).

Swanson, L. W., P. E. Sawchenko, S. Bérod, B. K. Hartmann, K. B. Koelle and D. E. Vanorden : An immunohistochemical study of the organization of catecholaminergic cells and terminal fields in the paraventricular and supraoptic nuclei of the hypothalamus. J. comp. Neurol. 196: 271-285 (1981).

Tappaz, M. L., M. Wassef, W. H. Oertel, L. Paut and J. F. Pujol : Light- and electron-microscopic immunocytochemistry of glutamic acid decarboxylase (GAD) in the basal hypothalamus: Morphological evidence for neuroendocrine-aminobutyrate (GABA). Neuroscience 9: 271-287 (1983).

Thomson, A. M.: Correlations between the firing of supraoptic neurons in slice of rat brain. Exp. Brain Res. 54: 217-224 (1984).

Vincent, J. D. and J. N. Hayward : Activity of single cells in the osmoreceptor-supraoptic nuclear complex in the hvpothalamus of the awaking rhesus monkey. Brain Res. 23: 105-108 (1970).

飯島浩一

率010 秋田市本道 1-1-1

秋田大学医学部

第二解剖学教室
Prof. Dr. Koichi Irjima

Department of Anatomy

Akita University School of Medicine

Akita, 010 Japan 